\title{
Common arterial trunk in a cat: a high-resolution morphological analysis with micro-computed tomography
}

DOI:

10.1016/j.jvc.2020.12.003

\section{Document Version}

Accepted author manuscript

Link to publication record in Manchester Research Explorer

\section{Citation for published version (APA):}

Nakao, S., Atkinson, A. J., Motomochi, T., Fukunaga, D., \& Dobrzynski, H. (2020). Common arterial trunk in a cat: a high-resolution morphological analysis with micro-computed tomography. Journal of Veterinary Cardiology, 34, 815. https://doi.org/10.1016/j.jvc.2020.12.003

\section{Published in:}

Journal of Veterinary Cardiology

\section{Citing this paper}

Please note that where the full-text provided on Manchester Research Explorer is the Author Accepted Manuscript or Proof version this may differ from the final Published version. If citing, it is advised that you check and use the publisher's definitive version.

\section{General rights}

Copyright and moral rights for the publications made accessible in the Research Explorer are retained by the authors and/or other copyright owners and it is a condition of accessing publications that users recognise and abide by the legal requirements associated with these rights.

\section{Takedown policy}

If you believe that this document breaches copyright please refer to the University of Manchester's Takedown Procedures [http://man.ac.uk/04Y6Bo] or contact uml.scholarlycommunications@manchester.ac.uk providing relevant details, so we can investigate your claim.

\section{OPEN ACCESS}




\section{Journal of Veterinary Cardiology}

\section{Common arterial trunk in a cat: a high-resolution morphological analysis with micro- computed tomography \\ --Manuscript Draft--}

\begin{tabular}{|c|c|}
\hline Manuscript Number: & JVC-D-19-00032R8 \\
\hline Article Type: & Case Report \\
\hline Keywords: & congenital heart disease; diagnostic imaging; echocardiography \\
\hline Corresponding Author: & $\begin{array}{l}\text { Shu Nakao, DVM, PhD } \\
\text { Ritsumeikan University } \\
\text { Kusatsu, Shiga JAPAN }\end{array}$ \\
\hline First Author: & Shu Nakao, DVM, PhD \\
\hline \multirow[t]{5}{*}{ Order of Authors: } & Shu Nakao, DVM, PhD \\
\hline & Andrew J Atkinson, PhD \\
\hline & Tomoki Motomochi, DVM \\
\hline & Daisuke Fukunaga, DVM \\
\hline & Halina Dobrzynski, PhD \\
\hline Abstract: & $\begin{array}{l}\text { A 6-month-old female cat presented with respiratory distress. Physical examination } \\
\text { showed a grade } 5 / 6 \text { holosystolic murmur with prominent precordial impulse over the } \\
\text { left cranial chest wall. Echocardiography revealed bilateral hypertrophy of the } \\
\text { ventricular walls, a dilated ascending aorta overriding the interventricular septum, a } \\
\text { membranous ventricular septal defect and no obvious pulmonary trunk or pulmonary } \\
\text { artery branches. Turbulent blood flow was detected around the ventricular septal } \\
\text { defect and ascending aorta. Follow-up assessment, } 12 \text { months later, revealed marked } \\
\text { and progressive biatrial dilation and biventricular hypertrophy. Four months after that, } \\
\text { the cat died of severe congestive heart failure. To make a definitive post-mortem } \\
\text { diagnosis, we performed contrast enhanced micro-computed tomography (CT) on the } \\
\text { ex vivo heart with micron-scale spatial resolution imaging and three-dimensional } \\
\text { reconstruction. Micro-CT analysis confirmed a common arterial trunk that bifurcated } \\
\text { into the left pulmonary artery and aorta } 5 \text { mm distally from the truncal valve. The } \\
\text { pulmonary trunk was absent. Slightly distal to the first branching, the common arterial } \\
\text { trunk further branched into the right pulmonary artery and ascending aorta, indicating } \\
\text { the aortic dominant form. Although CT angiography would be a preferred imaging } \\
\text { modality for living animals, micro-CT is a valuable tool for the ex vivo diagnosis of } \\
\text { complex cardiac anomaly, such as presented in this cat. }\end{array}$ \\
\hline Response to Reviewers: & $\begin{array}{l}\text { We do apologize that the revised manuscript_R7 was still inappropriate for publication } \\
\text { due to containing some issues that we should have corrected. In spite of this, we } \\
\text { appreciate that you have considered for publication in the Journal of Veterinary } \\
\text { Cardiology. According to your comments and the guide for authors, we have carefully } \\
\text { revised the manuscript. We hope this version of our manuscript is satisfactory for } \\
\text { publication in your Journal. }\end{array}$ \\
\hline
\end{tabular}


1 Title: Common arterial trunk in a cat: a high-resolution morphological analysis

2 with micro-computed tomography

3 Authors: \#a,b,c,g Shu Nakao, DVM, PhD, c,g Andrew J Atkinson, PhD, ${ }^{d}$ Tomoki Motomochi,

4 DVM, e Daisuke Fukunaga, DVM, \#c,f Halina Dobrzynski, PhD

5 Affiliations: a Department of Biomedical Sciences, College of Life Sciences,

6 Ritsumeikan University; ' ${ }^{b}$ Ritsumeikan Global Innovation Research Organization,

7 Ritsumeikan University, 1-1-1 Noji-higashi, Kusatsu, Shiga 525-8577 Japan; ' Division

8 of Cardiovascular Sciences, Faculty of Biology, Medicine and Health, University of

9 Manchester, 46 Grafton Street, Manchester M13 9NT United Kingdom; ${ }^{\text {d Motomochi }}$

10 Animal Hospital, 22-6 Karahashi-cho, Otsu, Shiga 520-0851 Japan; e CREA Animal 11 Hospital, 5-13-21 Aoyama, Otsu, Shiga 520-2101 Japan; ${ }^{f}$ Department of Anatomy,

12 Jagiellonian University Medical College, Świętej Anny 12, Cracow 31-008 Poland.

13 Short title: Common arterial trunk in a cat

14 \#Corresponding authors: Dr. Shu Nakao, snakao@fc.ritsumei.ac.jp and Dr. Halina 15 Dobrzynski, halina.dobrzynski@manchester.ac.uk

16 Current addresses: 1-1-1 Noji-higashi, Kusatsu, Shiga, Japan, 525-8577 (SN) and $3^{\text {rd }}$ 17 Floor, Core Technology Facility, 46 Grafton Street, Manchester, UK, M13 9NT (HD) 
118 Conflict of Interest Statement: The authors have no conflict of interest to declare.

20 Acknowledgements: We acknowledge the Engineering and Physical Science

21 Research Council (EPSRC) for funding the Henry Moseley X-ray Imaging Facility

22 which has been made available through the Royce Institute for Advanced Materials

23 through grants (EP/F007906/1, EP/F001452/1, EP/I02249X, EP/M010619/1,

$24 \mathrm{EP} / \mathrm{F} 028431 / 1, \mathrm{EP} / \mathrm{M} 022498 / 1$ and EP/R00661X/1). This work was also supported by

25 Fondation Leducq (TNE FANTASY 19CV03) awarded to HD and AJA 


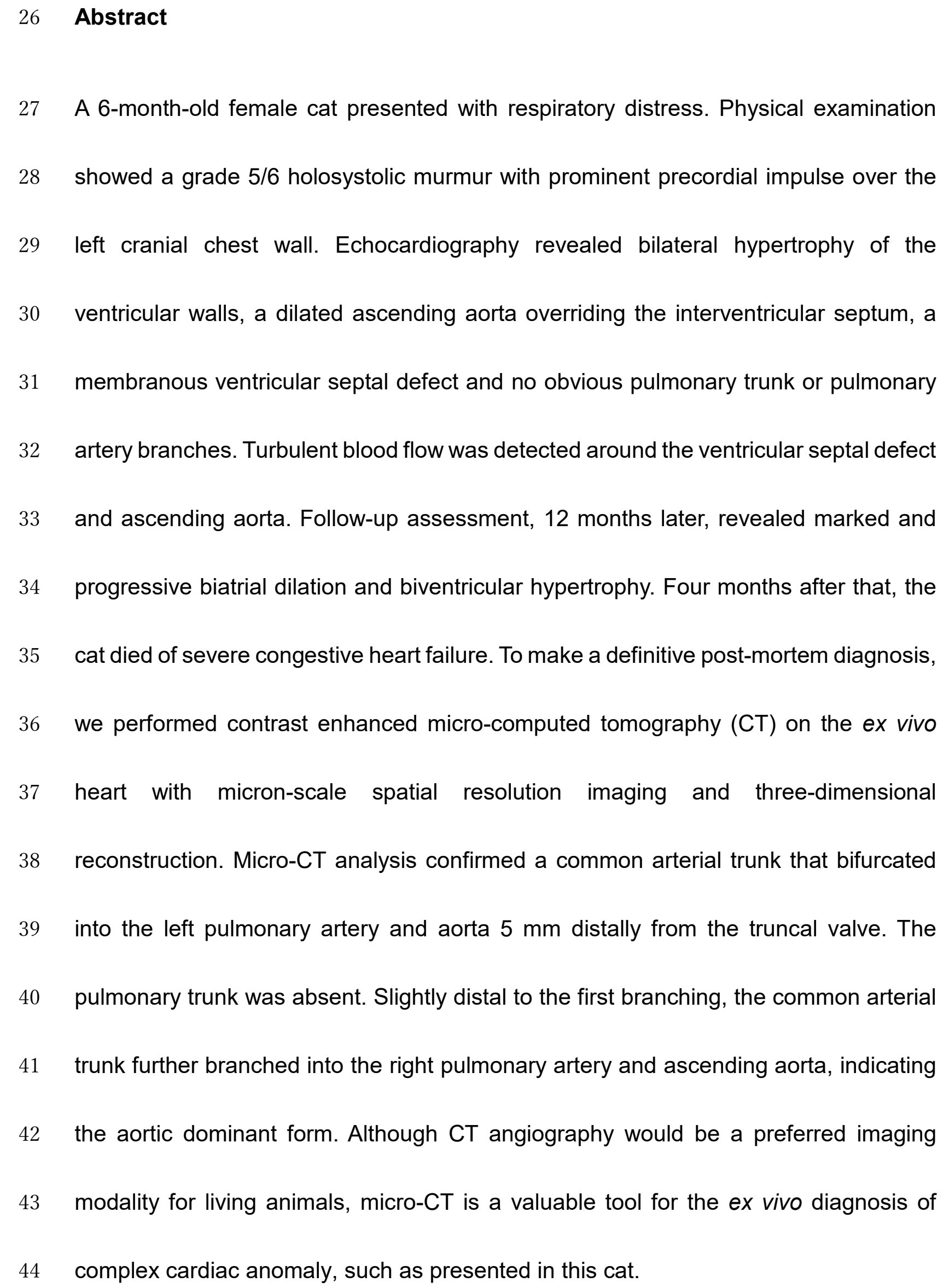




\section{Key Words}

Congenital heart disease; diagnostic imaging; echocardiography

Abbreviation table

\begin{tabular}{|l|l|}
\hline Abbreviations & Definition \\
\hline 3D & three-dimensional \\
\hline Ao & aortic arch \\
\hline CAT & common arterial trunk \\
\hline CT & computed tomography \\
\hline LA & left atrium \\
\hline LPA & left pulmonary artery \\
\hline LV & left ventricle \\
\hline RA & right atrium \\
\hline RPA & right pulmonary artery \\
\hline RV & right ventricle \\
\hline VS & interventricular septum \\
\hline VSD & ventricular septal defect \\
\hline
\end{tabular}


51 A 6-month-old, $2.6 \mathrm{~kg}$, intact female domestic short-haired cat was referred for further evaluation of a cardiac murmur detected incidentally prior to ovariohysterectomy. The cat exhibited normal activity and appetite at home according to the owner, but displayed heavy breathing with mild cyanosis at the hospital. A strong precordial impulse was palpable over the left cranial chest wall. Auscultation detected a regular 58 reference range. heart rhythm with $140-150$ beats per minute, a 5/6 grade holosystolic murmur and clear lung sounds. Complete blood count and serum biochemical profile were within a

Transthoracic echocardiography was performed with gentle restraint in the standing position to alleviate stress. The two-dimensional right parasternal short-axis ventricular view revealed bilateral ventricular hypertrophy, especially in the right ventricular wall with a flattening of the interventricular septum. The right parasternal long-axis four-chamber view revealed significant right atrial dilation $(17 \mathrm{~mm}$ in diameter) and a $5 \mathrm{~mm}$ membranous ventricular septal defect (VSD) (Fig. 1A and B, see also Videos 1 and 2 (available in Supplemental Material on-line)) [1]. The left atrium was also dilated (12 $\mathrm{mm}$ in diameter) [2]. Moreover, the aorta was significantly dilated and overriding the VSD. Colour-flow Doppler revealed turbulent flow in the area surrounding the VSD in diastole and the ascending aorta in systole, although the direction could not be specified due to the brief nature of the examination (Fig. 1A and 
70 B). The velocity of the regurgitant flow at the aortic valve was $3.0 \mathrm{~m} / \mathrm{s}$, estimating the 71 pressure gradient to be $36 \mathrm{~mm} \mathrm{Hg}$ using the simplified Bernoulli equation [3]. Normal

72 morphology of the right ventricular outflow tract including the pulmonary valve and the 73 pulmonary trunk could not be identified. Although the left pulmonary artery was 74 detected, there was no obvious communication between the pulmonary artery and 75 aorta. Based on the echocardiographic findings, a putative diagnosis of tetralogy of 76 Fallot was made at this point and enalapril hydrochloride $(0.25 \mathrm{mg} / \mathrm{kg}, \mathrm{PO}, \mathrm{q} 12 \mathrm{hr})$ 77 was initiated. cat's body weight had increased to $4.0 \mathrm{~kg}$. A grade $5 / 6$ holosystolic murmur and normal lung sounds were auscultated. The precordial impulse was more obvious than at the 81 initial presentation. Thoracic radiography revealed marked cardiomegaly, a shifted 82 cardiac axis with a rounded apex and distended pulmonary arteries (Fig. 2A and B). 83 Incomplete expansion of the caudal lung lobes and increased radiopacity in the left 84 cranial lung region were also observed (Fig. 2B), suggesting the existence of pleural effusion. An abbreviated echocardiographic examination was performed due to severe respiratory distress. The imaging revealed progression of right ventricular hypertrophy 87 and right atrial dilatation $(23 \mathrm{~mm}$ in diameter). The left atrial diameter had also 88 increased to $16 \mathrm{~mm}$ (Fig. $2 \mathrm{C}$ and D). Turbulent blood flow through the VSD was 
89 detected only in systole (Fig. $2 \mathrm{E}$ and F). The pulmonary valve and artery were not 90 visualised. With enalapril as only medication, the cat remained stable for 4 months until

91 it succumbed to respiratory failure.

92 The post-mortem examination was performed on the day the cat died (16 months 93 after the initial evaluation). The body condition score was 4 out of 5. Approximately 50 $94 \mathrm{~mL}$ of a modified transudate pleural effusion was present. The lungs and liver were 95 swollen, and they displayed irregularly reddish colour indicating moderate to severe 96 congestion. The heart was markedly enlarged, and the weight of the heart with some 97 great vessel tissue (Fig. $3 \mathrm{~A}$ and B) was $55 \mathrm{~g}$. The pericardium was slightly thickened 98 with a scant amount of pericardial effusion. The ventricles were concentrically 99 hypertrophied. The right and left auricles were markedly dilated and thickened (Fig. 1003 A). The pulmonary trunk and aortic arch were not anatomically separated from each 101 other (Fig. 3B). Our findings indicated the presence of a common arterial trunk. The 102 detailed morphology and communication between the ventricles and the great vessels 103 were still not evident.

104 To preserve the three-dimensional (3D) morphology of the heart with complex 105 anomaly, we performed micro-computed tomography (CT) analysis. The heart was 106 removed from the cat's chest and fixed in 10\% phosphate buffered formalin for further 
examination. The heart was stained in iodine-potassium iodide contrast agent ${ }^{\mathrm{h}}$ for 1 week and washed in water for 1 day to remove excess stain prior to micro-CT scanning ${ }^{i}$ [4]. The heart was scanned at $161 \mathrm{kV}, 136 \mu \mathrm{A}$, with a $200 \mu \mathrm{m}$ copper filter, and a voxel 110 resolution of $37 \mu \mathrm{m}$ was achieved. An imaging software was used to visualise the 111 cardiac morphology and segment structures. A micro-CT image revealed the left and 112 right pulmonary arteries separately branched directly from the common arterial trunk 113 (Fig. 3C). As observed with echocardiography, there was a prominent VSD and 114 absence of the normal communication from the right ventricle to the pulmonary trunk 115 (Fig. 3D). The common arterial trunk was the only outflow tract from the right ventricle 116 to the pulmonary arteries. The anatomical location of the mitral and tricuspid valves 117 was normal (Fig. 3E).

Further segmentation and visualisation of the micro-CT dataset revealed in detail 119 the abnormal connection between the great vessels. Five $\mathrm{mm}$ distal from the truncal 120 valve, the common arterial trunk branched into its distal portion and the left pulmonary 121 artery. A few mm distal to the first bifurcation, the trunk further branched into the right 122 pulmonary artery and the ascending aorta. Notably, this branching portion of the 123 common arterial trunk was markedly dilated and is the area where turbulent blood flow 124 was detected on echocardiography. Moreover, three distinctive arteries seem to 125 directly branch from the same region of the aortic arch. These united vessels were 
1126 probably composed of the right subclavian and left and right common carotid arteries

2

3 with a lack of/or remarkably shortened brachiocephalic artery. The origin of the left subclavian artery was isolated from this abnormal branching by a few $\mathrm{mm}$. Figure 4 and Videos 3 to 5 (available in Supplemental Material on-line) illustrate these findings.

130 In addition, the origin of the coronary arteries at the sinus Valsalva were clearly evident, 131 and normal branching of the coronaries was observed. Based on the micro-CT findings, 132 the feline heart was finally diagnosed as common arterial trunk with VSD. 


\section{Discussion}

3

Common arterial trunk is a rare congenital heart disease which has been reported in dogs, cats and large animals [5-15]. It can be defined as a single great vessel that arises from the cardiac base, forming the outlet of both ventricles [16]. This abnormality 137 appears to be due to complete failure of the separation of left and right ventricular 138 outflow tracts in the developing heart. The $180^{\circ}$ spiralling aorticopulmonary septum 139 normally partitions the embryonic truncus arteriosus into the pulmonary artery and 140 ascending aorta $[17,18]$. This septum creates the normal spiral relationship between 141 the aorta and pulmonary artery. The semilunar valves and their related sinuses are 142 created by the absorption and hollowing out of subendocardial tissue swellings at the 143 distal side of the truncal ridges. An absence of septation of the embryonic truncus 144 arteriosus by the conotruncal ridges leads to a single large artery that begins from the 145 base of the heart and supplies the systemic, pulmonary and coronary blood flows from 146 both ventricles through the VSD [16]. The Collet and Edwards classification of common 147 arterial trunk as persistent truncus arteriosus is based on the origin of the pulmonary 148 artery in humans [19]. According to this classification, the present case exhibiting 149 pulmonary arteries separately branched from close portions of the truncus would be 150 classified as type II. More recently, the Congenital Heart Surgery Nomenclature and 151 Database Project has published a simplified classification that subclassifies common 
152 arterial trunk hearts into aortic or pulmonary dominance, emphasising the principal morphological determinant of surgical outcome [20]. The present feline case of common arterial trunk would be assigned in the aortic dominant form.

Feline common arterial trunk cases have been reported previously. Some cases 156 were diagnosed as persistent truncus arteriosus, which is an older term of common 157 arterial trunk as mentioned above. In a case report from 1968, a 3-week-old cat was diagnosed with common arterial trunk using radiography and confirmed at necropsy 159 [5]. Chuzel et al. (2007) reported a case of common arterial trunk that was also 160 confirmed at necropsy in a 5-month-old cat displaying a single pulmonary trunk which 161 divided into left and right pulmonary arteries and a single aorta arising from the 162 common arterial trunk [7]. Nicolle et al. (2005) reported a common arterial trunk case 163 in a 6-year-old cat [12]. In this case, echocardiographic examination revealed no aorta 164 arising from the left ventricle. The animal had a stenosis of the common arterial trunk. 165 Furthermore, in a recent case report, echocardiography was used to reveal a dilated 166 arterial trunk overriding the interventricular septum with a large VSD in two young cats. 167 On further examination of these two animals using CT angiography, it became 168 apparent that one cat had common arterial trunk and the other had pulmonary atresia 169 with VSD [21]. Some animals, including the one presented in this study, can survive 170 for years with common arterial trunk, but generally the prognosis for these animals is 
1171 poor $[5,7,12,21]$.

2

To make a diagnosis of common arterial trunk, typical findings include: a large 173 VSD, a great vessel overriding the VSD or the right or left ventricle, absence of a 174 pulmonary trunk [16, 22]. Excluding the presence of a hypoplastic pulmonary artery is 175 also needed to differentiate common arterial trunk from tetralogy of Fallot or pulmonary 176 atresia (an extreme form of tetralogy of Fallot in which the main pulmonary artery is 177 present but severely stenotic $[19,23,24])$. Transthoracic echocardiography is a non178 invasive and widely accessible technique. Unfortunately, detailed echocardiographic 179 visualisation of the structure of the heart with complex anomalies is usually time 180 consuming and frequently limited due to intolerance for restraint particularly in patients 181 with respiratory distress [25]. Advanced imaging modalities and post-mortem 182 examination are thus important for definitive diagnosis of common arterial trunk. A 183 recent report described the utility of using CT angiography to diagnose a complex 184 congenital cardiac disease in cats similar to the case we are presenting [21]. Using CT 185 angiography, which enables the rapid visualisation of vascular and tissue morphology, 186 would be a preferred technique to be applied in living animals, in order to provide in 187 vivo differential diagnosis of complex congenital disease.

Micro-CT allows the detailed 3D visualisation of cardiac morphology. It offers high 
189 spatial resolution, low noise imaging compared to clinical CT scanners due to longer scan times (ranging from $30 \mathrm{~min}$ to $12 \mathrm{hr}$ ), higher frame averaging and the ability to adjust the geometric magnification by adjusting the distance between the source and sample. Micro-CT is well suited to the analysis of ex vivo tissues, but antemortem in 193 vivo micro-CT imaging is currently limited due to the X-ray dose required for high 194 resolution imaging and toxicity of the iodine contrast agent [26]. Furthermore, the 3D 195 micro-CT datasets can be freely explored and virtually segmented using 3D 196 visualisation softwarej [4]. Micro-CT data can also be explored immersively with the 197 use of virtual reality visualisation technology. Moreover, micro-CT data can be used to 198 create detailed 3D-printed organ models reproducing the gross anatomy and including 199 tissue density and fiber orientation. This can be a valuable tool for education. It must 200 be emphasized that micro-CT with iodine has become the gold standard in our 201 laboratory for studying healthy and diseased hearts. In addition, detailed 3D 202 anatomical models of these complex congenitally malformed hearts have the potential 203 to be used to perform computational modelling of cardiac blood flow [27, 28]. By 204 improving our understanding of the complex morphology in congenital heart diseases, 205 micro-CT can contribute to precise disease classification and treatment decision 206 making for future cases. 


\section{Footnote}

2

3

h $15 \% \mathrm{I}_{2} \mathrm{KI}$ solution containing $5 \%$ iodine (Sigma Aldrich, 207772) and $10 \%$

209 potassium iodide (Sigma Aldrich, 221945), Merck Life Science UK, Gillingham, UK

9

210 i Nikon XT H 320/225 kV High Flux equipped with PerkinElmer XRD 1611 XP flat

211 panel X-ray detector, Nikon Metrology NV, Leuven, Belgium

212 j Amira version 6.5, Thermo Fisher Scientific, Waltham, MA, USA 


\section{References}

3

4

[1] Visser LC, Sloan CQ, Stern JA. Echocardiographic assessment of right ventricular size and function in cats with hypertrophic cardiomyopathy. J Vet Intern Med 2017;31:668-77.

[2] Abbott JA, MacLean HN. Two-dimensional echocardiographic assessment of the feline left atrium. J Vet Intern Med 2006;20:111-9.

[3] Snider AR. Prediction of intracardiac pressures and assessment of ventricular function with Doppler echocardiography. Echocardiography 1987;4:305-20.

[4] Stephenson RS, Atkinson A, Kottas P, Perde F, Jafarzadeh F, Bateman M, laizzo PA, Zhao J, Zhang H, Anderson RH, Jarvis JC, Dobrzynski H. High resolution 3-dimensional imaging of the human cardiac conduction system from microanatomy to mathematical modeling. Sci Rep 2017;7:7188.

[5] Buergelt CD, Suter PF. Persistent truncus arteriosus in a cat. J Am Vet Med Assoc 1968;153:548-52.

[6] Chen HC, Bussian P, Whitehead JE. Persistent truncus arteriosus in a dog. Vet Pathol 1972;9:379-83.

[7] Chuzel T, Bublot I, Couturier L, Nicolier A, Rivier P, Mai W, Cadore JL. Persistent truncus arteriosus in a cat. J Vet Cardiol 2007;9:43-6.

[8] Downey RS, Liptrap RM. An unusual congenital cardiac defect in a dog. Can 
Vet J 1966;7:233-8.

[9] Jesty SA, Wilkins PA, Palmer JE, Reef VB. Persistent truncus arteriosus in two Standardbred foals. Equine Vet Educ 2007;19:307-11.

[10] Kurosawa TA, Gunasekaran T, Sanders R, Carr E. Common arterial trunk in a 3-day-old Alpaca cria. Case Rep Vet Med 2016;2016:4609126.

[11] Monne Rodriguez JM, Chantrey J, Unwin S, Verin R. Cardiac truncus arteriosus in an Eastern Black Rhinoceros (Diceros bicornis michaeli). J Comp Pathol 2017;157:276-9.

[12] Nicolle AP, Tessier-Vetzel D, Begon E, Carlos Sampedrano C, Pouchelon JL, Chetboul V. Persistent truncus arteriosus in a 6-year-old cat. J Vet Med A Physiol Pathol Clin Med 2005;52:350-3.

[13] Schwarzwald C, Gerspach C, Glaus T, Scharf G, Jenni R. Persistent truncus arteriosus and patent foramen ovale in a Simmentaler x Braunvieh calf. Vet Rec 2003;152:329-33.

[14] Sojka JE. Persistent truncus arteriosus in a foal. Equine Pract 1987;9:19-26.

[15] Steyn PF, Holland P, Hoffman J. The angiocardiographic diagnosis of a persistent truncus arteriosus in a foal. J S Afr Vet Assoc 1989;60:106-8.

[16] Webb GD, Smallhorn JF, Therrien J, Redington AN. Congenital heart disease. In: Bonow RO, Mann DL, Zipes DP, Libby PL, editors. Braunwald's Heart 
Disease: A Textbook of Cardiovascular Medicine. 9th ed. Philadelphia: Saunders; 2011, p. 1411-67.

[17] Kloesel B, DiNardo JA, Body SC. Cardiac embryology and molecular mechanisms of congenital heart disease: a primer for anesthesiologists. Anesth Analg 2016;123:551-69.

[18] Neeb Z, Lajiness JD, Bolanis E, Conway SJ. Cardiac outflow tract anomalies. Wiley Interdiscip Rev Dev Biol 2013;2:499-530.

[19] Collett RW, Edwards JE. Persistent truncus arteriosus: a classification according to anatomic types. Surg Clin North Am 1949;29:1245-70.

[20] Russell HM, Jacobs ML, Anderson RH, Mavroudis C, Spicer D, Corcrain E, Backer CL. A simplified categorization for common arterial trunk. J Thorac Cardiovasc Surg 2011;141:645-53.

[21] Markovic LE, Scansen BA, Potter BM. Role of computed tomography angiography in the differentiation of feline truncus arteriosus communis from pulmonary atresia with ventricular septal defect. J Vet Cardiol 2017;19:514-22.

[22] Penny D, Anderson RH. Common arterial trunk. In: Anderson RH, Baker EJ, Penny D, Redington AN, Rigby ML, Wernovsky G, editors. Pediatric Cardiology. 3rd ed. Philadelphia: Churchill Livingstone; 2009, p. 859-74.

[23] Fisher EW, Lee R, Pirie HM, Evans KG. Pseudo truncus arteriosus in a dog--a 
case report. J Small Anim Pract 1974;15:627-35.

[24] Lafargue RT, Vogel JHK, Pryor R, Blount SG. Pseudotruncus arteriosus. Am J Cardiol 1967;19:239-46.

[25] Forney S. Dyspnea and tachypnea. In: Ettinger SJ, Feldman EC, editors. 


\section{$1287 \quad$ Figure legends}

Fig.1 The right parasternal long-axis views of echocardiography from the cat with common arterial trunk (CAT) at the first presentation. (A) and (B) Long-axis views with a colour flow doppler mode in the diastolic (A) and systolic (B) phases. (A) Markedly dilated CAT, thickened myocardial wall of the right ventricle (RV) and interventricular septum and a membranous ventricular septal defect $\left({ }^{*}\right)$ accompanied by turbulent flow are observed. There is regurgitation from the CAT into the right and left ventricles through the ventricular septal defect $\left(^{*}\right)$. (B) Turbulent flow is broadly observed in the dilated CAT. See also Videos 1 and 2 (available in Supplemental Material on-line). CAT: common arterial trunk; LA: left atrium; LV: left ventricle; RV: right ventricle.

Fig. 2 Follow-up imaging from the cat with common arterial trunk (CAT) 12-month after the initial presentation. (A) and (B) left-to-right (A) and dorsal-to-ventral (B) images of thoracic radiography display severe cardiac enlargement, prominent pulmonary arteries and vessels and moderate pleural effusion. (C) and (D) The right parasternal long-axis four-chamber views of echocardiography in the diastolic (A) and systolic (B) phases visualise markedly dilated right atrium (RA) and thickened 
myocardial wall of the right ventricle (RV). Pleural effusion ( $\dagger$ ) is also indicated. $(E)$ and (F) The right parasternal long-axis views of the left ventricular outflow tract in the diastolic (E) and systolic (F) phases show that markedly dilated CAT. Turbulent blood flow around the CAT and ventricular septal defect $\left({ }^{*}\right)$ is observed. CAT: common arterial trunk; LA: left atrium; LV: left ventricle; RA: right atrium; RV: right ventricle.

Fig. 3 Postmortem findings of the heart from the cat with common arterial trunk

312 (CAT). (A) The appearance of the feline heart shows enlarged right atrium (RA) and 313 hypertrophied right (RV) and left (LV) ventricles with the rounded apex. (B) An enlarged 314 photograph of the boxed area in A shows CAT alongside the right (RPA) and left (LPA) 315 pulmonary arteries which seem to originate from the root of the CAT. No evidence of 316 the right ventricular outflow tract $\left(^{*}\right)$ suggesting hypoplasia. (C) A longitudinal-axis 317 micro-computed tomography (CT) image of the feline heart represents separately 318 branching into LPA and RPA from CAT. (D) A micro-CT image of the left ventricular 319 outflow tract shows CAT which overrides a prominent ventricular septal defect (VSD). 320 Markedly hypertrophied ventricular walls are also visualised. (E) A micro-CT image of 321 a four-chamber view of the feline heart shows the atrioventricular valves located at the 322 normal positions (arrowheads). Ao: aortic arch; CAT: common arterial trunk; LA: left 
1323 atrium; LPA: left pulmonary artery; LV: left ventricle; RA: right atrium; RPA: right

2

3

pulmonary artery; RV: right ventricle; VS: interventricular septum; VSD: ventricular septal defect.

Fig. 4 The detailed morphology of communication among the great vessels in the feline heart with common arterial trunk (CAT). (A) Three-dimensional reconstructed feline heart with CAT. (B) A segmented image of the CAT, right (RPA) 330 and left (LPA) pulmonary arteries and aortic arch (Ao) visualising the communication 331 among the great vessels. (C) An intracavity view of B. (D) An intracavity view from the 332 other side of B. (E) A short axis view illustrating the branching from CAT into RPA and 333 LPA. The arrows indicate arteries abnormally branching from the Ao. Scale bars $=5$ $334 \mathrm{~mm}$. See also Videos 3 to 5 (available in Supplemental Material on-line). Ao: aortic 335 arch; CAT: common arterial trunk; LA: left atrium; LPA: left pulmonary artery; LV: left 336 ventricle; RA: right atrium; RPA: right pulmonary artery; RV: right ventricle. 
Video 1 Video1_CDI_CAT.avi

A colour-flow doppler echocardiography cine of a long-axis view of the ventricular outflow tract showing turbulent flow in the common arterial trunk.

Video 2 Video2_CDI_VSD.avi

A colour-flow doppler echocardiography cine of a long-axis view of the ventricular outflow tract showing turbulent flow around the ventricular septal defect.

Video 3 Video3_micro-CT1.avi

A three-dimensional (3D)-reconstruction micro-computed tomography (micro-CT) image of the appearance of the great vessels of the cat with common arterial trunk.

Video 4 Video4_micro-CT2.avi

A 3D-reconstruction micro-CT image of a cut-surface of the great vessels of the cat with common arterial trunk showing the 
origin of the pulmonary arteries.

A 3D-reconstruction micro-CT image of the

Video 5 Video5_micro-CT3.avi

great vessels of the cat with common arterial trunk with a sweeping cut-surface showing the origin of the pulmonary arteries. 


\section{Fig. 1}
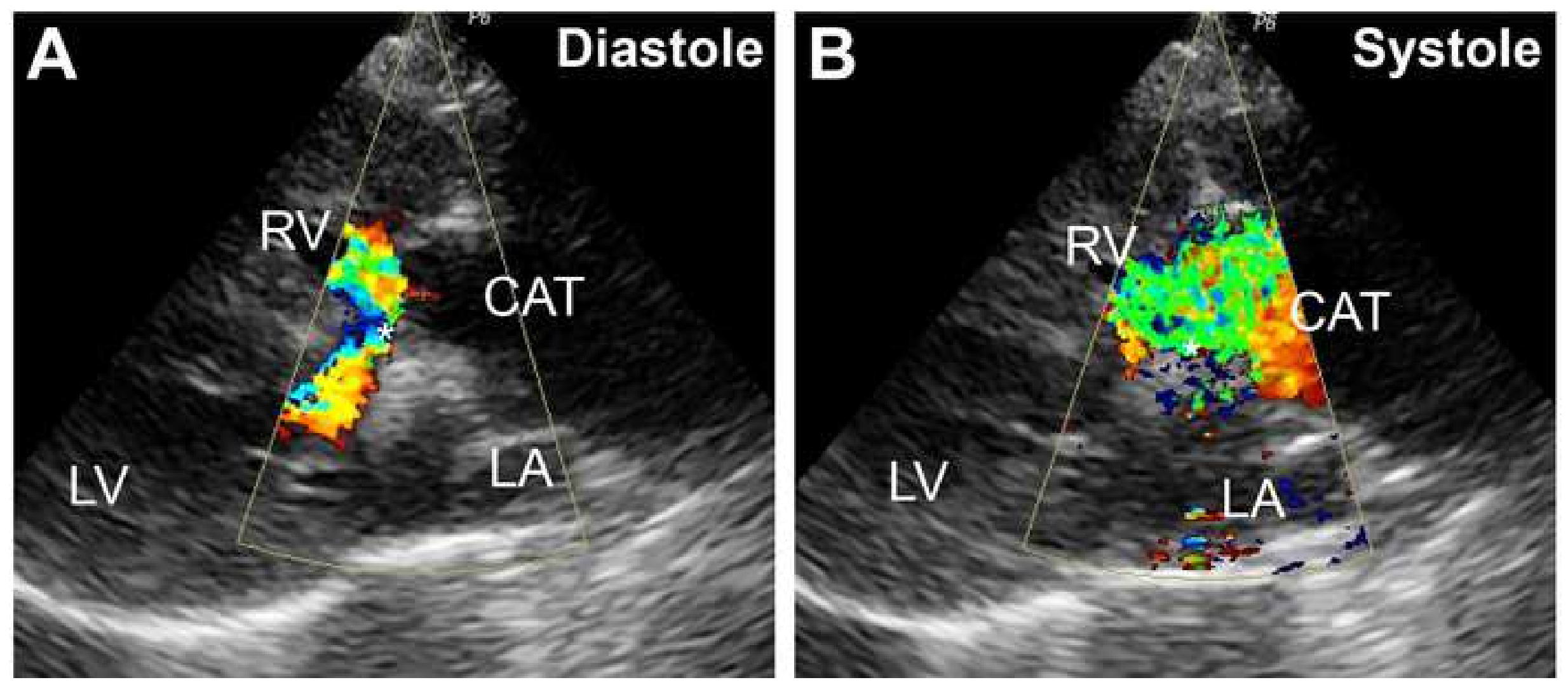


\section{Fig. 2}
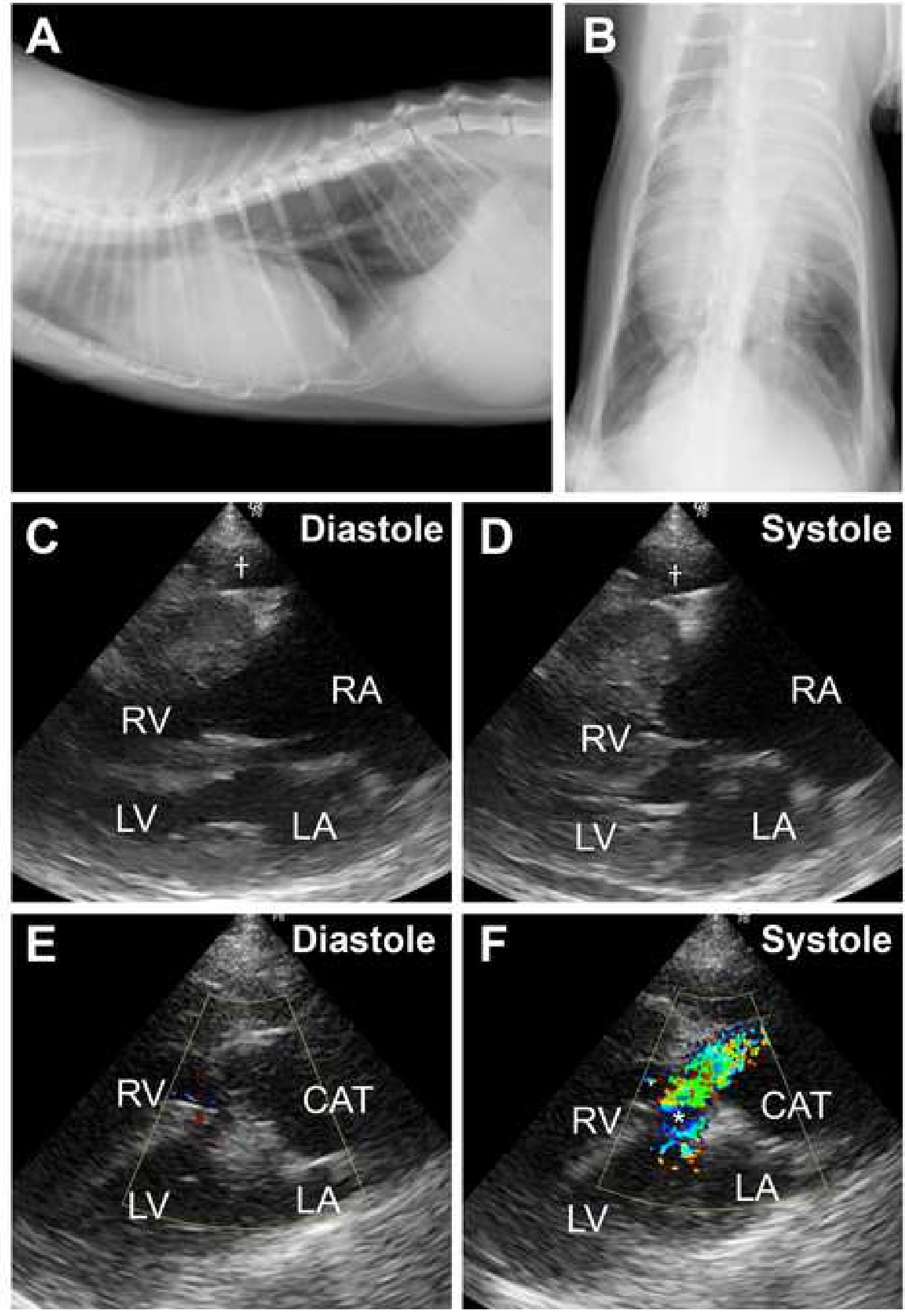


\section{Fig. 3}
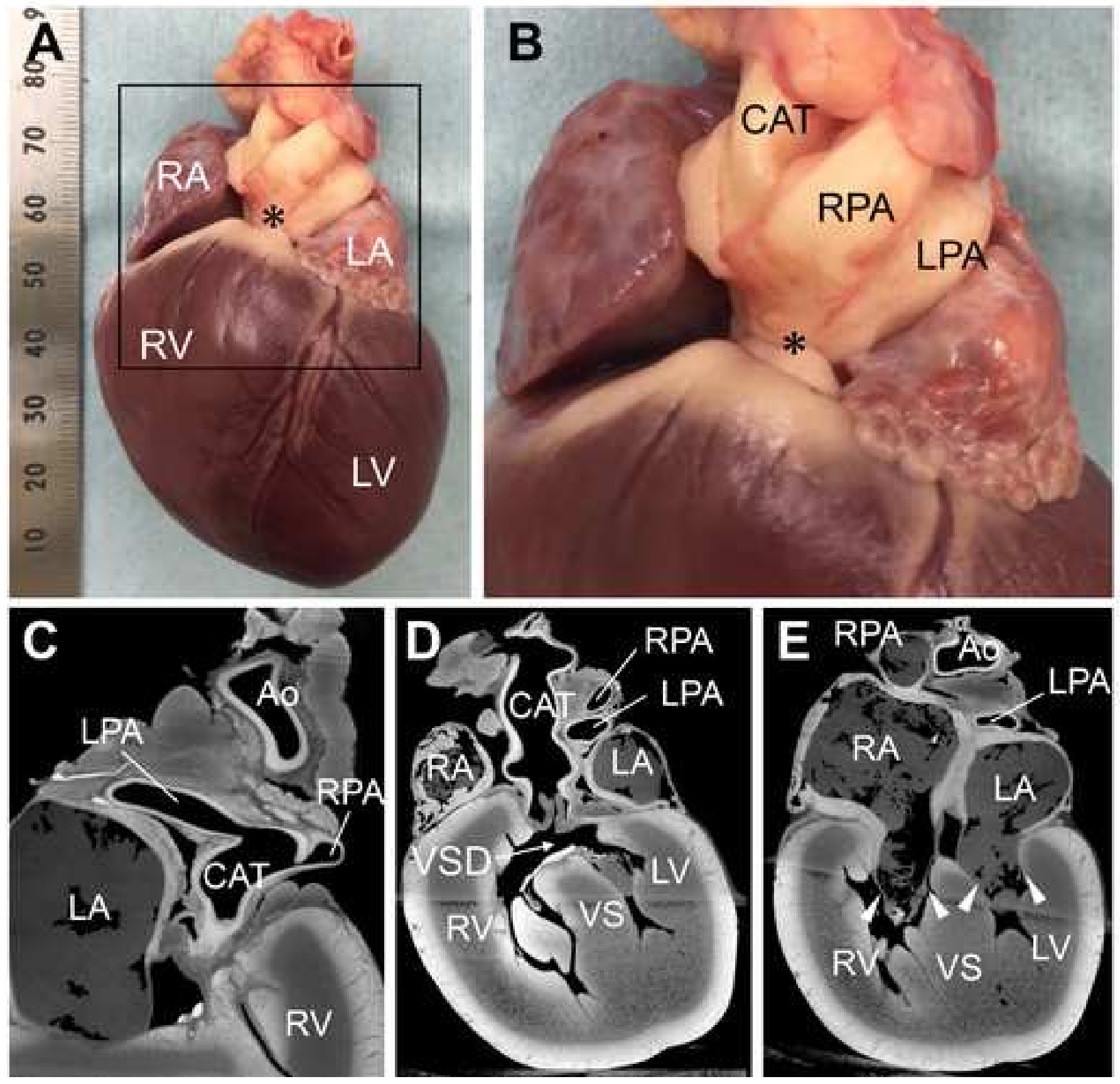


\section{Fig. 4}

A

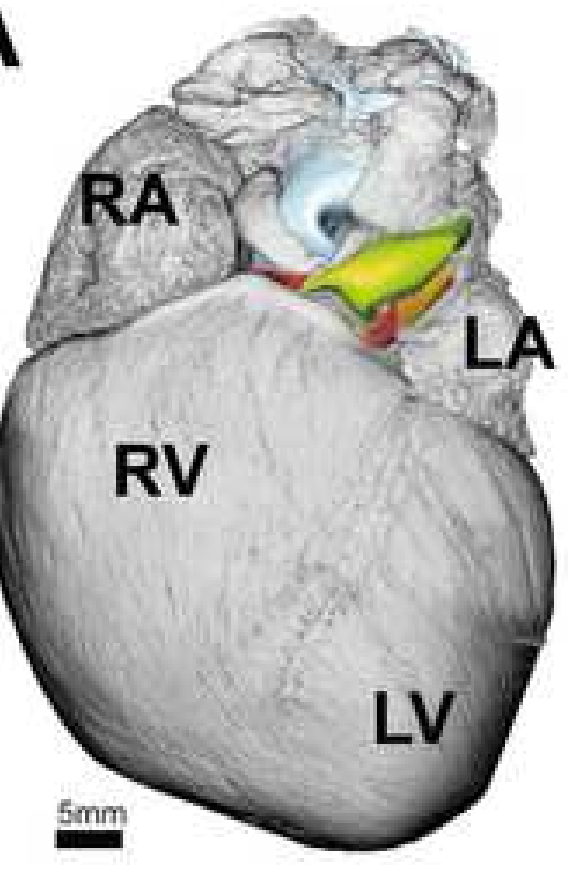

B

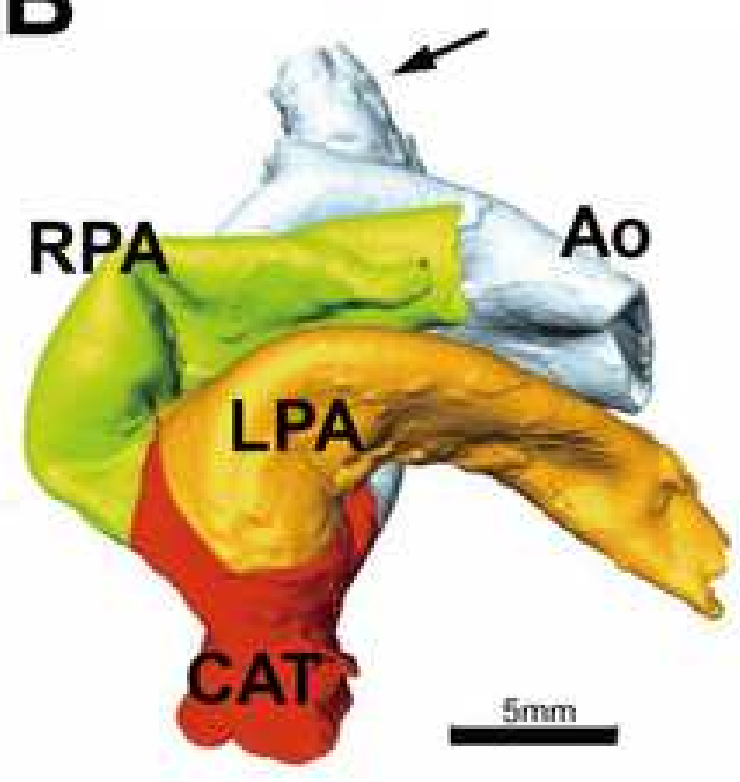

D
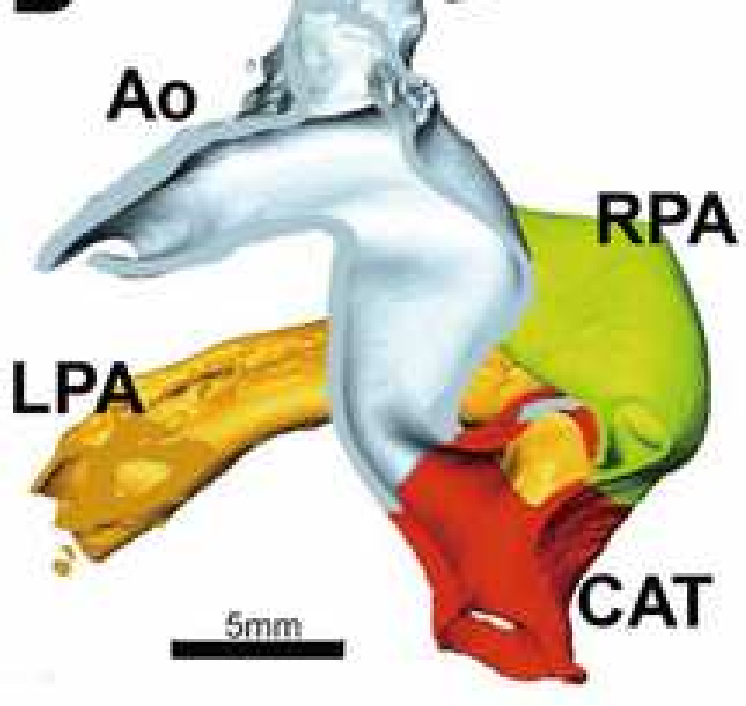

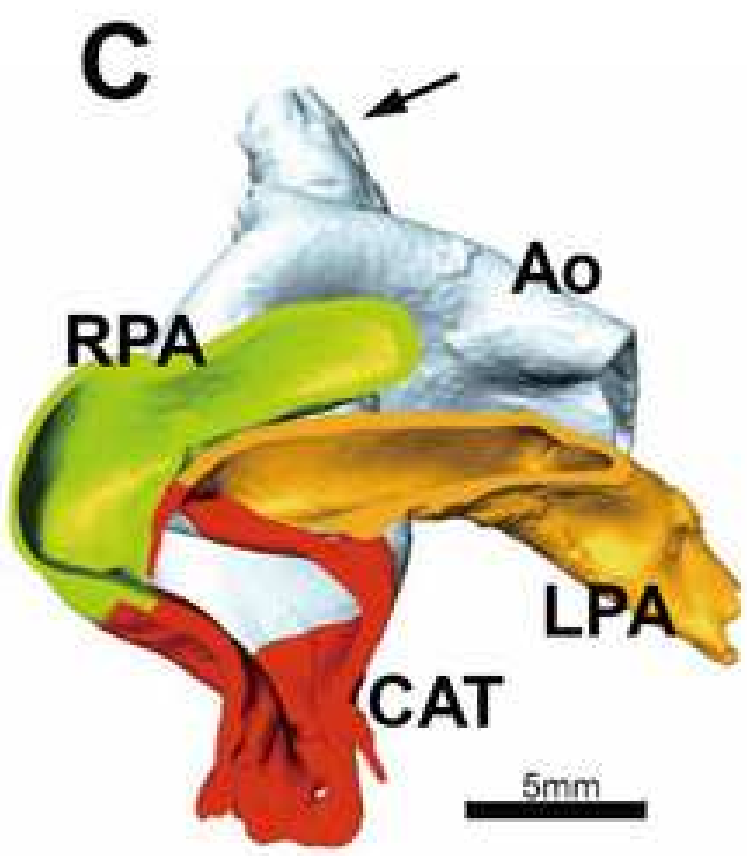

E

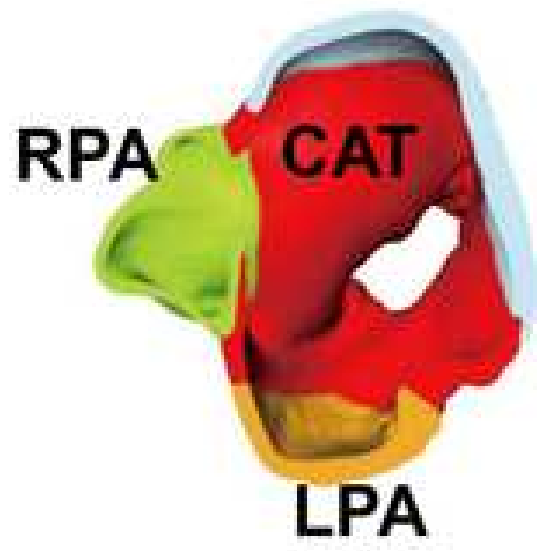


Click here to access/download Video Video1_CDI_CAT.avi 


\section{Click here to access/download \\ Video 2 CDI_VSD.avi}


Click here to access/download

\section{Video
Video3_microCT1.avi \\ Video
Video3_microCT1.avi}


Click here to access/download Video

Video4_microCT2.avi 
Click here to access/download Video
Video5_microCT3.avi 